\title{
A randomized controlled trial to validate the Alice PDX ambulatory device
}

\author{
Georg Nilius' \\ Ulrike Domanski' \\ Maik Schroeder' \\ Karl-Josef Franke' \\ Anke Hogrebe' \\ Laurent Margarit ${ }^{2}$ \\ Maria Stoica ${ }^{2}$ \\ Marie-Pia d'Ortho $0^{2,3}$ \\ 'HELIOS-Klinik Ambrock, Universität \\ Witten-Herdecke, Hagen, Germany; \\ ${ }^{2}$ Service de Physiologie - Explorations \\ Fonctionnelles DHU FIRE, Groupe \\ Hospitalier Bichat-Claude Bernard, \\ Assistance Publique-Hopitaux de \\ Paris, ${ }^{3}$ Université Denis Diderot \\ Paris 7, Paris, France
}

This article was published in the following Dove Press journal:

Nature and Science of Sleep

6 June 2017

Number of times this article has been viewed

Background: Obstructive sleep apnea (OSA) is a highly prevalent condition; however, the majority of patients remain undiagnosed. There is a potential to expand the diagnostic capacity of sleep laboratories. The study objective was to validate a portable respiratory monitoring device (Alice PDX) against polysomnography (PSG) in the laboratory and to assess its reliability at home.

Methods: A total of 85 patients with suspected OSA ( $80 \%$ male, mean age $49.1 \pm 13.5$ years, body mass index $29.7 \pm 6.9 \mathrm{~kg} / \mathrm{m}^{2}$, Epworth Sleepiness Scale 10.0 \pm 5.1 ) were randomized to 3 diagnostic nights: 1 night simultaneous in-laboratory PSG and PDX recording; 1 night selfapplied PDX at home, and 1 night in-laboratory PSG. Study data were manually scored according to American Academy of Sleep Medicine criteria.

Results: The Alice PDX was in diagnostic agreement with simultaneously recorded reference PSG in $96.4 \%$ of studies. In $2.4 \%$ of studies the in-laboratory PDX underestimated and in $1.2 \%$ of studies it overestimated the apnea hypopnea index (AHI). The difference between the AHI from the reference PSG and the home study was similar to the difference between the PSGs (2.79 vs $0.79, p=0.08)$.

Conclusion: In a population with a high suspicion of OSA, the Alice PDX showed a high level of diagnostic agreement with a simultaneous PSG and performed valid home diagnostic studies for OSA. If manually scored, the portable device can be used by sleep specialists for diagnosing moderate-to-severe obstructive sleep apnea in cases with a high pretest probability for the disease over a wide range of disease severity. The technology can be deployed reliably outside of the sleep laboratory setting.

Keywords: sleep apnea, diagnostic, portable device, ambulant monitoring, polysomnography

\section{Introduction}

Obstructive sleep apnea (OSA) is a disorder of great significance for the affected patients. The repetitive collapse of upper airways, associated with increased arousal reactions and oxygen desaturations, leads to increased daytime sleepiness, ${ }^{1}$ reduction of quality of life (QOL), ${ }^{2}$ and increased frequency of traffic accidents. ${ }^{3}$ With OSA, there is a high prevalence of severe secondary diseases such as arterial hypertension, ${ }^{4}$ atrial fibrillation, ${ }^{5}$ myocardial infarctions, ${ }^{6}$ stroke, and cancer, ${ }^{7}$ with a reduction of life expectancy. ${ }^{8}$

While previous evaluations assumed that at least $4 \%$ of males and $2 \%$ of females in the working age population are suffering from OSA, ${ }^{9}$ a study found a considerable increase in the prevalence to $10 \%$ and $17 \%$ among males (30- to 49 -year old and 50to 70 -year old, respectively) and $3 \%$ and $9 \%$ among females (30- to 49 -year old and
Correspondence: Georg Nilius HELIOS Klinik Hagen Ambrock, Ambrocker Weg 60, 5809I Hagen, Germany

Tel +49233 I9742000

Email georg.nilius@helios-kliniken.de 
50- to 70 -year old, respectively $)^{10}$ presuming an increased prevalence of obesity and longer lifespan as causes. A more recent study shows a higher prevalence $(23.4 \%$ in females and $49.7 \%$ in males), which might be attributable to increased recording and scoring techniques. ${ }^{11}$ It has to be assumed that the majority of patients are not diagnosed. ${ }^{12}$

The diagnostic gold standard to detect OSA is attended, inpatient, monitored cardiorespiratory polysomnography (PSG), ${ }^{13}$ which requires high personnel and financial expenditures. To wade through the flood of patients, many portable monitoring (PM) systems are available. These devices can be categorized into 4 system groups. ${ }^{14}$ The class 3 systems with not $<4$ parameters are usually used for outpatient diagnostic measurements. According to recommendations of the American Academy of Sleep Medicine (AASM), PM systems are eligible for diagnosing OSA in patients with high pretest probability and without severe comorbidities. ${ }^{15}$ In light of the growing heterogeneity of the outpatient diagnostic devices, a recent paper proposed a new classification based upon the parameters the device records called SCOPER (S(leep), C(ardiovascular), O(ximetry), P(osition), E(ffort), and $\mathrm{R}$ (espiratory)). ${ }^{16}$

Even with this comprehensive approach, the authors point out that each of the systems needs to be compared to the gold standard to ascertain the conventional quality criteria for diagnostic tests including sensitivity, specificity, and the positive predictive value (PPV).

The aims of this study were to determine the diagnostic accuracy of a PM device (Alice PDX; Philips Respironics, Murrysville, PA, USA) compared to PSG during laboratory recordings and to assess the ability of the device to predict the presence of OSA in the home environment. A study design with 4 sleep studies (2 PSG, 2 PM) on 3 nights was chosen to assess the effects on the apnea hypopnea index (AHI), which may occur due to a night to night variability, sleep laboratory versus home environment, and PM versus PSG settings.

\section{Methods}

This single-blind, randomized cross-over study was performed at 2 European sites and conducted in accordance with the amended Declaration of Helsinki with ethics committee approval from the University Witten Herdecke (105/2008) and from the ethics committee "Ile de France 1" and ANSM (National Security Agency of Medicines and Health Products) (RCB:2009-A00081-56). All participants signed informed consent before the study. The study is registered under Nr. ISRCTN62641592. Preliminary findings of this study were already presented at congresses: the 27th Annual Meeting of the Associated Professionals Sleep Societies, LLC Baltimore (abstract published in the Journal of Sleep and Sleep Disorders Research Volume 36, 2013) and the European Respiratory Society in Amsterdam (abstract published in the European Respiratory Journal 38, 2011)

\section{Selection of participants}

Each center recruited half of the participants. Adult patients, $\geq 21$ years, were eligible for the study if they had suspected OSA (loud and irregular snoring with observed breathing interruptions and increased daytime sleepiness [ie, a group with high pretest probability]). Also 11 participants who reported snoring but did not have OSA (simple snorers) were included.

Exclusion criteria were previous OSA diagnosis; presence or suspicion of another sleep disorder; acute unstable illness; any medically unstable condition resulting from chronic cardiac, pulmonary, or other internal diseases; a requirement for oxygen or mechanical ventilation; drug or alcohol abuse; excessive intake of drugs affecting the central nervous system; sedatives or other drugs which impair sleep; psychiatric or neurological diseases; unstable thyroidal dysfunction; and chronic pain syndromes.

\section{Clinical examinations}

All participants underwent complete clinical history and physical examination (body mass index [BMI], neck circumference, measured at the level of cricothyroid membrane, and blood pressure). A questionnaire about symptoms of snoring, sleepiness, and the associated features of OSA was completed along with the Epworth Sleepiness Scale (ESS).

\section{Protocol}

All participants underwent diagnostic evaluation over 3 nonconsecutive nights in a randomized order. One diagnostic evaluation was conducted with the Alice PDX PM recorder (device class IIa, EC certificate No. G1 160715581 051) in the participant's home (PDX home). Another diagnostic evaluation was conducted with attended in-laboratory PSG (PSG single) at the sleep laboratory by using Alice (Alice 5; Philips Respironics). The third diagnostic evaluation consisted of an attended in-laboratory study with simultaneous PSG and PDX polygraphy (PG) recording (PSG simultaneous) which were both carried out by a sleep technician.

\section{Overnight attended polysomnography}

A standard PSG montage was used for each attended inlaboratory diagnostic evaluation and included electroen- 
cephalogram (EEG, F4, C4, O2), electrooculogram (EOG), chin electromyogram (EMG), leg EMG, electrocardiogram (ECG), breathing effort parameters, airflow parameters, oxygen saturation $\left(\mathrm{SpO}_{2}\right.$, finger probe, Oximetry board Massimo), and body position, according to AASM recommendations. The data were anonymized and then manually scored. Sleep stages, arousals, and abnormal respiratory events were quantified according to AASM 2007 criteria. $^{17}$

\section{PM with Alice PDX}

The Alice PDX is a portable monitor which according to the SCOPER System is categorized as $\mathrm{S}_{0} \mathrm{C}_{4} \mathrm{O}_{1} \mathrm{P}_{2} \mathrm{E}_{1} \mathrm{R}_{1}$. It includes oxygen saturation $\left(\mathrm{SpO}_{2}\right.$, finger probe, Oximetry board Nonin), pulse rate (from the oximeter probe), airflow (pressure-based airflow with snore detection through a nasal cannula and thermistor), thoracic and abdominal effort (inductance plethysmography), and body position. The device includes an event button.

For the in-laboratory measurements, the technician set up both the systems. For the home measurement, the participants were instructed how to set up the system by themselves. The participants were advised with verbal and written instructions and were given a brief demonstration. Participants were asked to activate the event marker to indicate "lights out" and "lights on" and any time they get up for $>15$ minutes. The participants were called in the morning to determine the validity of their PG recording by using the "good study indicator." When illuminated, the "good study indicator" confirms at least 4 hours of recording. If $<4$ hours of good data were present, the cause was remotely identified and resolved before a second recording was initiated.

\section{Scoring procedures}

To minimize the inter-scorer variability, each center had a dedicated and experienced scoring technician. A training program was conducted for both study sites, and these standards were followed for scoring:

Apnea: at least a 90\% reduction of airflow for at least 10 seconds (regardless if central, obstructive, or mixed). At least $90 \%$ of the event's duration meets the amplitude reduction criteria for apnea.

Hypopnea criteria $\mathrm{A}: \mathrm{A} \geq 30 \%$ reduction in airflow for at least 10 seconds with $\geq 4 \%$ desaturation (definition used for PSG and PDX).

Hypopnea criteria $B$ : $A \geq 50 \%$ reduction in airflow for at least 10 seconds with $\geq 3 \%$ desaturation (definition used for PSG and PDX) or terminated by an arousal (definition used for PSG, American Sleep Disorders Association rules).
Each evaluation underwent manual review by the scoring technician, who was blinded to the date and time of the recordings and the patient's medical information. Each PSG and PDX evaluation was scored twice - once with hypopneas classified according to the AASM hypopnea criteria A and once according to criteria B.

\section{Clinical agreement levels}

From a clinical point of view, it was chosen to categorize 3 different levels of agreement between both diagnostic systems.

The rate of diagnostic agreement was calculated for the PDX-Lab and PSG and PDX-Home and PSG in a manner similar to White. ${ }^{18}$ An AHI $>30$ is generally accepted as the cutoff for severe OSA. Therefore, any paired result $>30$ was accepted as diagnostic agreement, and in cases with an inlaboratory PSG AHI $<30$, a deviation of $\leq 10$ was classified as agreement and a deviation $>10$ was classified as under- or overestimation (Table 3 ).

\section{Statistical analysis}

The various sleep studies were performed to address the effects of night to night variability, home and sleep laboratory environments, and full attended PSG versus PM measurements. The main endpoint was to compare the difference of PM at home and PSG with 2 consecutive PSGs.

The sample size calculation was performed based upon the data of White ${ }^{18}$ with a standard deviation of 6.0. Assuming a broader range in AHI, a standard deviation of 9.0 was selected. It was assumed that the minimum important difference to detect was an AHI of 5. With a power of $90 \%$ and an alpha of $0.05, \sim 70$ patients were required to use the Alice PDX at home before or after PSG. A combined dropout rate and equipment failure or data loss rate of $12 \%$ for the unattended home study was predicted so that $\sim 80$ patients had to be recruited.

Baseline characteristics were summarized with descriptive statistics. The indices for manually scored in-laboratory and simultaneous PSGs were computed as the number of events per hour of sleep, and for PDX, the number of events per hour of recording time. AHI and secondary respiratory parameters were compared between the 4 diagnostic evaluations by using the Friedman test, due to the asymmetry of the data. Post-hoc pairwise comparisons were performed by using the Wilcoxon signed-rank test, with Bonferroni correction. The difference in AHI values between the simultaneous laboratory PSG and at-home PDX was compared to the difference between the 2 PSGs conducted on separate nights, by using a Wilcoxon signed-rank test. 
In each comparison, the simultaneous in-laboratory PSG was considered the reference PSG. Intraclass correlation (ICC) was performed by using a 2-way random model measuring absolute agreement for single measures. Bland-Altman plots of the AHI data were generated for visualization of the bias and limits of agreement. Receiver operating characteristic (ROC) analyses were performed at AHI cutoffs of 5, 15, and 30 to compute the area under the curve (AUC), as well as sensitivity, specificity, positive and negative likelihood ratios, and PPVs and negative predictive values (NPVs) for the given device-detected event values. The rates of diagnostic agreement, overestimation, and underestimation were calculated according to the criteria described in Table 3. The data were analyzed by using SPSS (Version 20; IBM Corporation, Armonk, NY, USA) and Analyse-it (Version 3.8; Leeds, UK). Statistical trends were considered significant at $p<0.05$.

The randomization sequence was generated by using the SAS software. The randomization sequence contained 15 balanced blocks of 6 codes by using the different sequence possibilities and was stratified by patient type (suspected OSA or snorer).

\section{Results}

One hundred and twenty-six individuals were screened between September 2009 and January 2012 and in that sample 120 were eligible but 22 refused to participate. Therefore, 98 individuals were randomized. Eighty-five participants (74 OSA and 11 simple snorers) had complete data and were included in the final data analysis (Figure 1).

Baseline characteristics are shown in Table 1. Participants were middle aged, predominantly male, with a mean BMI approaching the threshold for obesity with a large neck circumference. Hypertension (systolic blood pressure $>140$ $\mathrm{mmHg}$ or diastolic blood pressure $>90 \mathrm{mmHg}$ ) was present in $24 \%$ of the participants. Other than the simple snorers being significantly younger, the demographic variables were not significantly different from participants with a suspicion of OSA.

The simultaneous average saturation differed between the PDX and PSG recording by $\sim 0.9 \%$; however, the simultaneous mean desaturation index showed near identical values (14.8 in PSG, 14.7 in PG). All the results are shown in Table 2.

The PDX was in diagnostic agreement with the simultaneously recorded reference PSG in $96.4 \%$ of the evaluations. In $2.4 \%$ of the evaluations, PDX underestimated the AHI and in $1.2 \%$ it overestimated the AHI. The PDX home recording versus simultaneous PSG showed underestimation in $5.9 \%$ and overestimation in $10.6 \%$ of the cases (Table 3 ). The median difference between the AHI from the reference PSG and the PDX-home study was similar to the difference

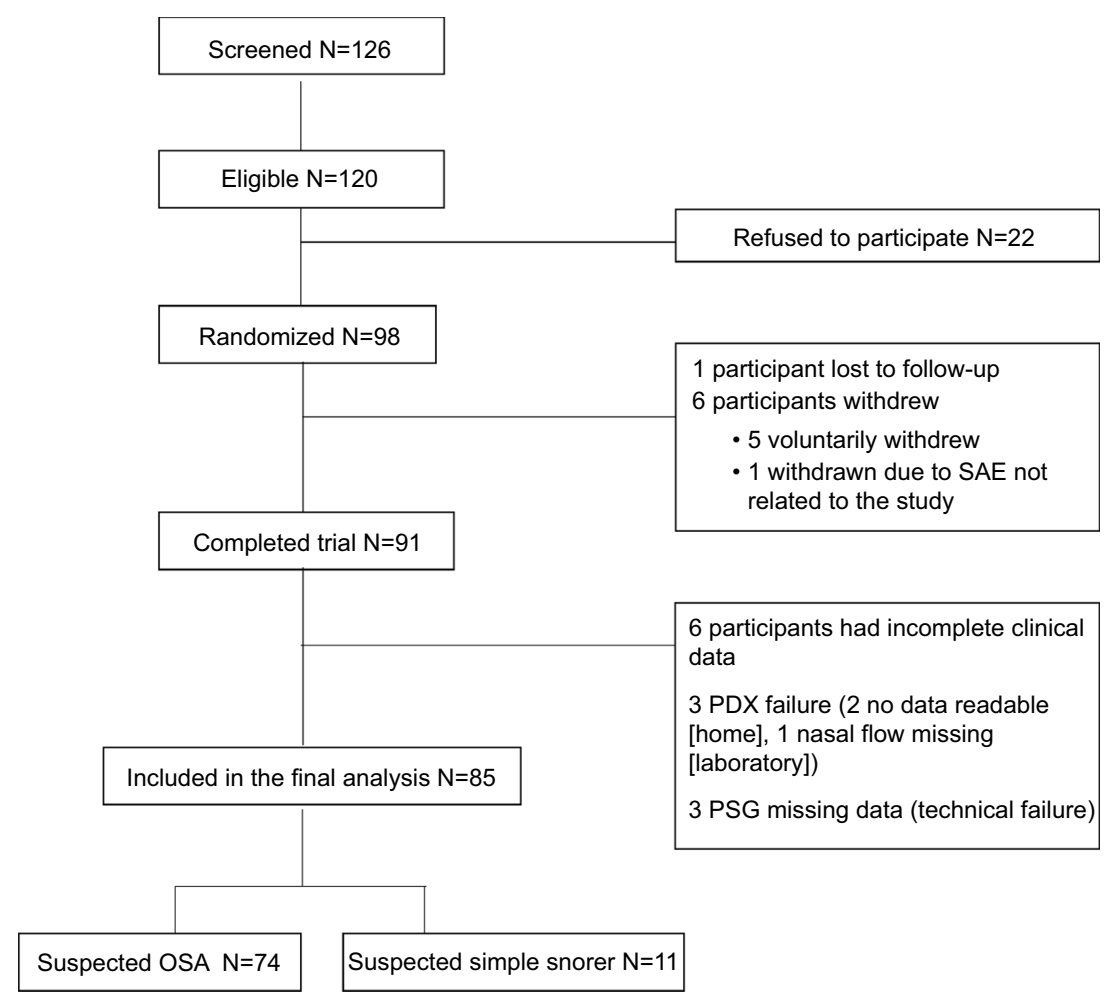

Figure I Flowchart of the study.

Abbreviations: SAE, serious adverse event; PSG, polysomnography; OSA, obstructive sleep apnea. 
Table I Patient characteristics

\begin{tabular}{|c|c|c|c|c|}
\hline Characteristics & Entire group & $\begin{array}{l}\text { Suspected } \\
\text { OSA }(N=74)\end{array}$ & $\begin{array}{l}\text { Suspected simple } \\
\text { snorers }(\mathrm{N}=\mathrm{II})\end{array}$ & $\begin{array}{l}p \text {-value (OSA } \\
\text { vs non-OSA) }\end{array}$ \\
\hline Age (years) & $49.1 \pm 13.5$ & $50.6 \pm 12.9$ & $40.5 \pm 14.3$ & $0.025^{a}$ \\
\hline Male $(\mathrm{n}[\%])^{*}$ & $68(80)$ & $58(78.4)$ & $10(90.9)$ & $0.450^{\mathrm{b}}$ \\
\hline BMI $\left(\mathrm{kg} / \mathrm{m}^{2}\right)$ & $29.7 \pm 6.9$ & $29.9 \pm 7.1^{* *}$ & $28.5 \pm 6.0$ & $0.553^{\mathrm{a}}$ \\
\hline Neck circumference $(\mathrm{cm})$ & $4 \mid .6 \pm 5.1$ & $41.8 \pm 5.2^{* *}$ & $41.0 \pm 4.3$ & $0.657^{\mathrm{a}}$ \\
\hline \multicolumn{5}{|l|}{ Blood pressure } \\
\hline Systolic (mmHg) & $133.7 \pm 15.8$ & $133.3 \pm 15.0$ & $136.8 \pm 2 \mid .9$ & $0.516^{\mathrm{a}}$ \\
\hline Diastolic (mmHg) & $77.5 \pm 11.1$ & $77.3 \pm 11.2$ & $80.0 \pm 10.8$ & $0.540^{\mathrm{a}}$ \\
\hline ESS & $10.0 \pm 5.1$ & $10.1 \pm 5.2$ & $9.9 \pm 5.1$ & $0.924^{\mathrm{a}}$ \\
\hline ESS $\geq$ II (n [\%]) & $44(51.8)$ & $38(5 \mid .4)$ & $6(60.0)$ & $0.74 I^{b}$ \\
\hline \multicolumn{5}{|l|}{ Medical conditions ( $\mathrm{n}[\%]$ ) } \\
\hline Hypertension & $33(38.8)$ & $29(39.2)$ & $4(36.4)$ & \\
\hline Diabetes & $6(7.1)$ & $4(5.4)$ & $2(18.2)$ & \\
\hline Chronic heart diseases & $8(9.4)$ & $7(9.5)$ & $\mathrm{I}(9.1)$ & \\
\hline
\end{tabular}

Notes: Values are given as the mean \pm SD or count (\%). ${ }^{*} \mathrm{OSA}$ classification was not recorded for I participant. ${ }^{* *} \mathrm{~N}=73$ due to missing data. andependent-sample $t$-test. 'Fisher's exact test.

Abbreviations: BMI, body mass index; ESS, Epworth Sleepiness Scale; SD, standard deviation; OSA, obstructive sleep apnea.

Table 2 Results (mean and SD) of all home and laboratory studies

\begin{tabular}{|c|c|c|c|c|c|c|c|c|c|c|c|c|}
\hline \multirow{2}{*}{$\begin{array}{l}\text { Scoring } \\
\text { criteria } \\
\text { AASM } 2007\end{array}$} & \multirow[t]{2}{*}{ Sleep parameters } & \multirow[t]{2}{*}{ Units } & \multirow[t]{2}{*}{$\begin{array}{l}\text { Index } \\
\text { time base }\end{array}$} & \multicolumn{2}{|c|}{$\begin{array}{l}\text { Separate } \\
\text { PSG } \\
\end{array}$} & \multicolumn{2}{|c|}{$\begin{array}{l}\text { Simultaneous } \\
\text { PSG }\end{array}$} & \multirow[t]{2}{*}{$\begin{array}{l}\text { Index } \\
\text { time base }\end{array}$} & \multicolumn{2}{|c|}{$\begin{array}{l}\text { Simultaneous } \\
\text { PDX } \\
\end{array}$} & \multicolumn{2}{|c|}{$\begin{array}{l}\text { At-home } \\
\text { PDX }\end{array}$} \\
\hline & & & & Mean & SD & Mean & SD & & Mean & SD & Mean & SD \\
\hline & TRT & $(\min )$ & TIB & 457.6 & 55.3 & 453.4 & 47.6 & TRT & 422.1 & 72.4 & 423.3 & 91.0 \\
\hline & TST & $(\min )$ & TST & 373.2 & 76.8 & 364.1 & 65.8 & - & - & - & - & - \\
\hline & Total arousal index & $(\mathrm{n} / \mathrm{h})$ & TST & 29.3 & 15.9 & 29.8 & 16.0 & - & - & - & - & - \\
\hline & Average saturation & (\%) & TST & 94.8 & 1.8 & 94.8 & 1.6 & TRT & 93.9 & 1.9 & 93.6 & 2.1 \\
\hline & Apnea index & $(\mathrm{n} / \mathrm{h})$ & TST & 13.7 & 17.5 & 14.2 & 17.8 & TRT & 12.2 & 15.8 & II.I & 16.0 \\
\hline \multirow[t]{5}{*}{ Нyр A } & Hypopnea index & $(\mathrm{n} / \mathrm{h})$ & TST & 4.6 & 7.6 & 4.9 & 7.4 & TRT & 5.3 & 6.3 & 5.1 & 5.2 \\
\hline & $\mathrm{AHI}$ & $(\mathrm{n} / \mathrm{h})$ & TST & 18.2 & 20.2 & 19.0 & 20.2 & TRT & 17.4 & 17.7 & 16.3 & 17.6 \\
\hline & Supine AHI & $(\mathrm{n} / \mathrm{h})$ & TST supine & 26.8 & 25.6 & 27.1 & 27.7 & TRT supine & 24.9 & 25.2 & 24.7 & 25.4 \\
\hline & Respiratory arousal index & $(\mathrm{n} / \mathrm{h})$ & TST & 10.3 & 14.6 & 10.6 & 13.6 & - & - & - & - & - \\
\hline & Desaturation index & $(\mathrm{n} / \mathrm{h})$ & TST & 13.4 & 18.3 & 14.8 & 18.8 & TRT & 14.7 & 15.9 & 13.9 & 16.1 \\
\hline \multirow[t]{5}{*}{ Нур В } & Hypopnea index & $(\mathrm{n} / \mathrm{h})$ & TST & 6.7 & 8.0 & 7.1 & 8.2 & TRT & 7.7 & 6.7 & 7.6 & 6.0 \\
\hline & $\mathrm{AHI}$ & $(\mathrm{n} / \mathrm{h})$ & TST & 20.7 & 20.7 & 21.3 & 20.6 & TRT & 19.9 & 18.0 & 18.7 & 18.2 \\
\hline & Supine AHI & $(\mathrm{n} / \mathrm{h})$ & TST supine & 29.3 & 25.7 & 30.3 & 28.4 & TRT supine & 28.3 & 26.5 & 28.1 & 26.3 \\
\hline & Respiratory arousal index & $(\mathrm{n} / \mathrm{h})$ & TST & 14.3 & 15.3 & 14.5 & 14.5 & - & - & - & - & - \\
\hline & Desaturation index & $(n / h)$ & TST & 18.5 & 19.7 & 19.9 & 20.7 & TRT & 20.7 & 17.8 & 19.1 & 17.7 \\
\hline
\end{tabular}

Notes: Hypopnea A: flow amplitude drop $\geq 30 \%$ with desaturation $>4 \%$ without considering arousals; Hypopnea $\mathrm{B}$, flow amplitude drop $\geq 50 \%$ with either desaturation $>3 \%$ or arousal or both.

Abbreviations: AASM, American Academy of Sleep Medicine; PSG, polysomnography; SD, standard deviation; AHI, apnea hypopnea index; TRT, total recording time; TST, total sleep time; TIB, time in bed.

between the two PSGs $(0.6$ vs $0.0, p=0.08)$ for hypopnea criteria $\mathrm{A}$ and 1.0 versus $0.1(p=0.463)$ for hypopnea criteria B including arousals.

There was a strong significant correlation between the AHI from the reference PSG and the in-laboratory PDX (ICC 0.95), the at-home PDX (0.79), and the separate PSG (0.90) (all $p<0.001$ ) (Figure 2). With a Friedman test, there were no significant differences between any of the AHI values ( $p=0.207)$. There were statistical differences with respect to Apnea Index, Hypopnea Index, average $\mathrm{O}_{2}$ saturation, and oxygen desaturation index in some of the comparisons.
The Bland-Altman analyses generally showed a good agreement between AHI values from the reference PSG and the in-laboratory PDX, the at-home PDX, and the separate PSG (Figure 3). In comparison to the reference PSG, the Alice PDX tended to overestimate the AHI at lower AHIs and underestimate the AHI at higher AHIs when performed in the laboratory and at home. In comparison to the reference PSG, the separate PSG had no bias toward over- or underestimating the AHI at lower and higher AHIs. Sensitivity, specificity, and PPVs and NPVs, and likelihood ratios at AHI cutoff values of 5,15 , and 30 were calculated for the AHI from the reference 
Table 3 Diagnostic agreement of AHI for the simultaneous (in-laboratory) PSG and PDX, the in-laboratory PSG and at-home PDX, and the simultaneous in-laboratory and separate PSGs, and diagnostic agreement/disagreement criteria

\begin{tabular}{llll}
\hline & $\begin{array}{l}\text { Simultaneous PDX versus } \\
\text { simultaneous PSG }\end{array}$ & $\begin{array}{l}\text { At-home PDX versus } \\
\text { simultaneous PSG }\end{array}$ & $\begin{array}{l}\text { Separate PSG versus } \\
\text { simultaneous PSG }\end{array}$ \\
\hline Agreement (\%) & 96.5 & 83.5 & 85.9 \\
Overestimation (\%) & 1.2 & 5.9 & 3.5 \\
Underestimation (\%) & 2.4 & 10.6 & 10.6 \\
Diagnostic classification & PSG AHI & PDX AHI & \\
Agreement & $\geq 30$ & $\geq 30$ \\
Agreement & $<30$ & PSG AHI $\leq 10$ & \\
Overestimation & $<30$ & PSG AHI $+>10$ & \\
Underestimation & $<30$ & PSG AHI $\rightarrow>10$ & \\
\hline
\end{tabular}

Abbreviations: $\mathrm{AHI}$, apnea hypopnea index; PSG, polysomnography.
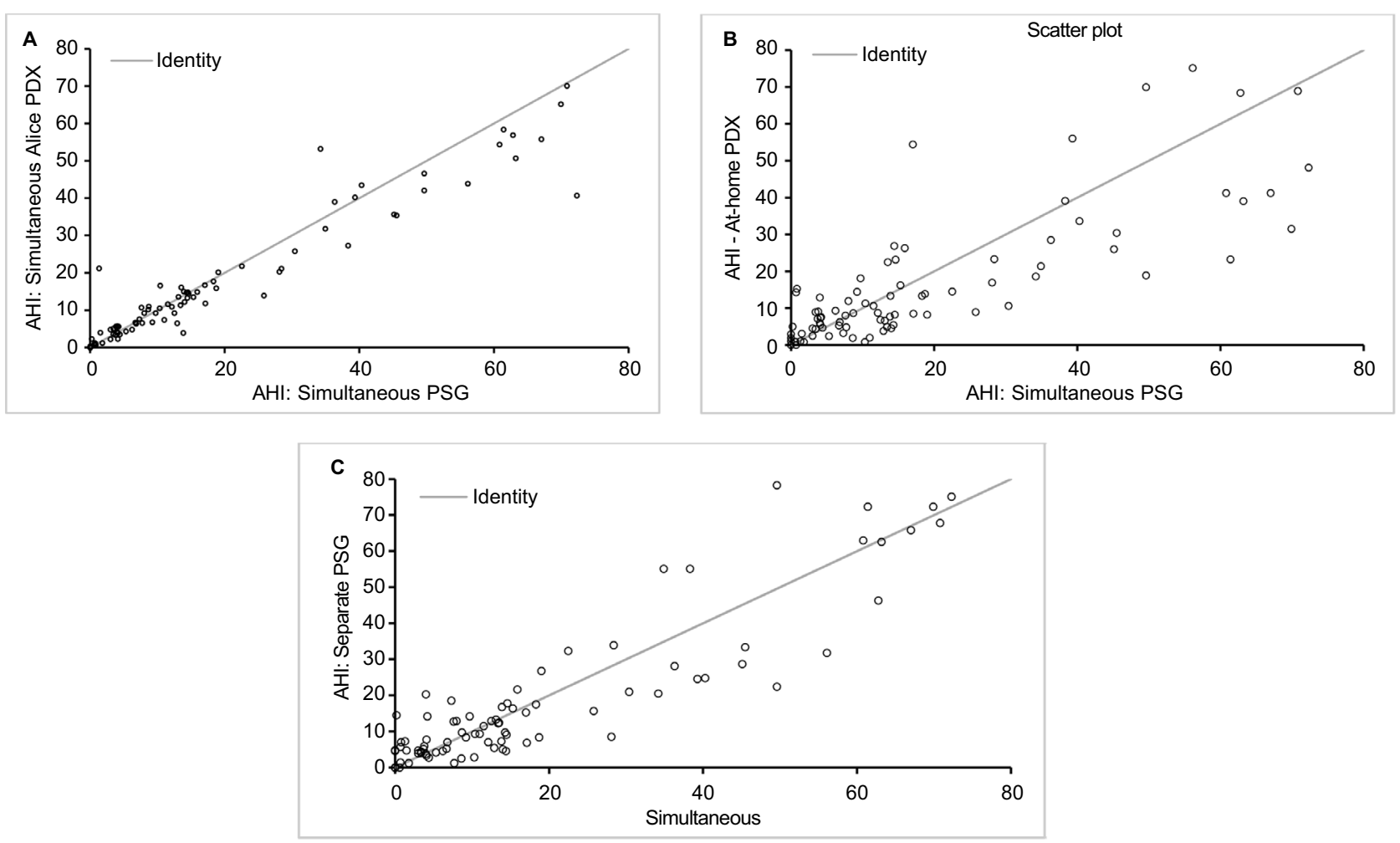

Figure 2. ICCs between AHls from: (A) simultaneous (in-laboratory) PSG and in-laboratory PDX (ICC $=0.95, p<0.00 \mathrm{I})$; (B) simultaneous in-laboratory PSG and at home PDX $(I C C=0.79, p<0.00 \mathrm{I})$; and $(\mathbf{C})$ simultaneous in-laboratory PSG and separate PSG $($ ICC $=0.90, p<0.00 \mathrm{I})$.

Abbreviations: PSG, polysomnography; AHI, apnea hypopnea index; ICC, intraclass correlation.

PSG and the in-laboratory PDX, the at-home PDX, and the separate PSG (Table 4).

By using AHI cutoff values of 5, 15, and 30, the AUC was at least 0.84 (0.94 for AHI > 15) in all comparisons (Figure 4).

There were $6(6.6 \%)$ instances of technical problems noted during the diagnostic evaluations. This failure rate is consistent with that from a previous publication. ${ }^{19}$

\section{Discussion}

The major finding is that the PDX portable monitor showed a high sensitivity and specificity in quantifying AHI when compared to in-laboratory diagnostic PSG in patients with suspected OSA, and that the results from the home PG with the PDX are quite comparable to a full in-laboratory PSG, especially in moderate (AHI >15)-to-severe (AHI >30) OSA.

Every comparison of home PM with attended PSG in the sleep laboratory suffers from several methodological problems: the situation at home is quite different to the sleep laboratory environment and it is doubtful that the sleep characteristics in the home setting can be fully captured in the laboratory. Increased supine sleep position increases OSA severity, ${ }^{20}$ and higher sleep efficiency and proportion of REM (rapid eye movement) sleep and slow wave sleep at home has been confirmed. ${ }^{21}$

It must be noted that at home the patient has to apply the sensors by himself and the time base of analyses refers to 

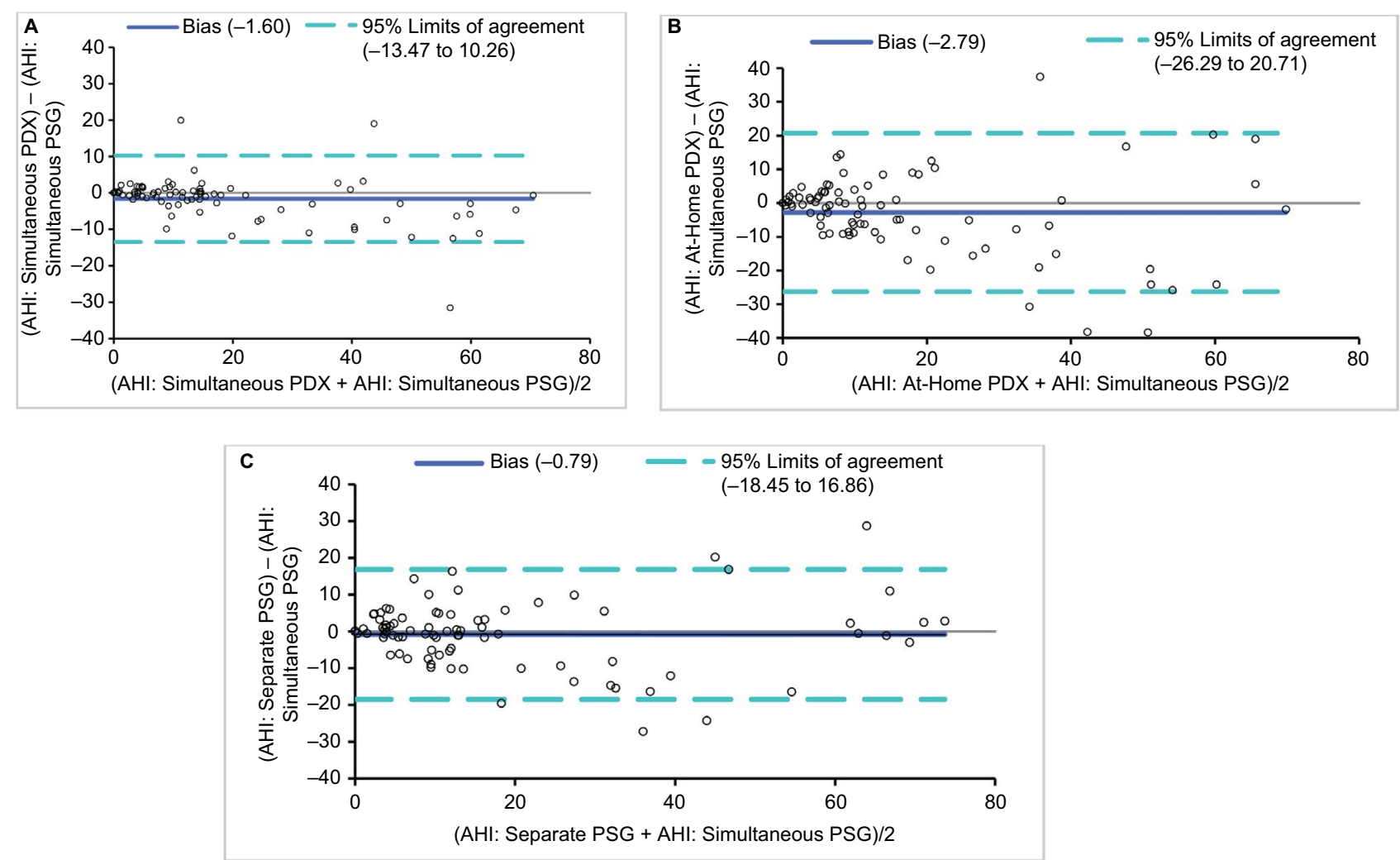

Figure 3 Bland-Altman plots of: (A) simultaneous (in-laboratory) PSG and in-laboratory PDX; (B) simultaneous in-laboratory PSG and at-home PDX; and (C) simultaneous in-laboratory PSG and separate PSG.

Abbreviations: AHI, apnea hypopnea index; PSG, polysomnography.

Table 4 Sensitivity, specificity, PPV and NPV, and positive and negative likelihood ratios for different AHI cutoffs

\begin{tabular}{|c|c|c|c|c|c|c|c|}
\hline & Optimal AHI* & Sensitivity (\%) & Specificity (\%) & PPV (\%) & NPV (\%) & $\begin{array}{l}\text { Positive } \\
\text { likelihood ratio }\end{array}$ & $\begin{array}{l}\text { Negative } \\
\text { likelihood ratio }\end{array}$ \\
\hline \multicolumn{8}{|l|}{$\mathrm{AHI} \geq 5$} \\
\hline In-laboratory PDX & 5.7 & 95 & 96 & 98 & 89 & 23.8 & 0.05 \\
\hline At-home PDX & 7.4 & 77 & 76 & 88 & 58 & 3.2 & 0.3 \\
\hline Separate PSG & 7.0 & 80 & 80 & 91 & 63 & 4.0 & 0.3 \\
\hline \multicolumn{8}{|l|}{$\mathrm{AHI} \geq \mathrm{I} 5$} \\
\hline In-laboratory PDX & 14.7 & 90 & 91 & 85 & 94 & 9.8 & 0.1 \\
\hline At-home PDX & 12.9 & 87 & 85 & 77 & 92 & 5.9 & 0.2 \\
\hline Separate PSG & 14.2 & 90 & 91 & 85 & 94 & 9.8 & 0.1 \\
\hline \multicolumn{8}{|l|}{$\mathrm{AHI} \geq 30$} \\
\hline In-laboratory PDX & 21.8 & 100 & 100 & 100 & 100 & $* *$ & 0 \\
\hline At-home PDX & 18.6 & 90 & 91 & 75 & 97 & 9.8 & 0.1 \\
\hline Separate PSG & 20.5 & 95 & 94 & 83 & 98 & 15.4 & 0.1 \\
\hline
\end{tabular}

Notes: *AHI of test measure (left column) at which there is an optimal balance between sensitivity and specificity. **Undefined due to division by zero.

Abbreviations: PSG, polysomnography; AHI, apnea hypopnea index; PPV, positive predictive value; NPV, negative predictive value.

sleep time in PSG versus recording time in PM. To address these questions, 3 sleep studies were performed. To evaluate the night to night variability, the in-laboratory PSG was performed twice and the difference ( $\mathrm{PSG}_{\text {sim }}$ minus $\mathrm{PSG}_{\text {single }}$ ) of those 2 nights was not significant $(p=0.079)$ compared to the difference between the simultaneously performed PSG with the PDX at home $\left(\mathrm{PSG}_{\mathrm{sim}}\right.$ minus $\left.\mathrm{PDX}_{\text {home }}\right)$. The effect of different criteria for the hypopnea definition on the AHI was very small, and the supine and total AHI were comparable between the home and sleep laboratory environment. The ICC for the AHI from the reference PSG and the in-laboratory PDX is similar to that reported in an international study (ICC 0.95 for the overall AHI) ${ }^{22}$ comparing manual scoring between sites from 9 sleep centers, so that the technical systems can be regarded as closely comparable. The scoring technicians were blinded to minimize the influence in the manual evaluation. 

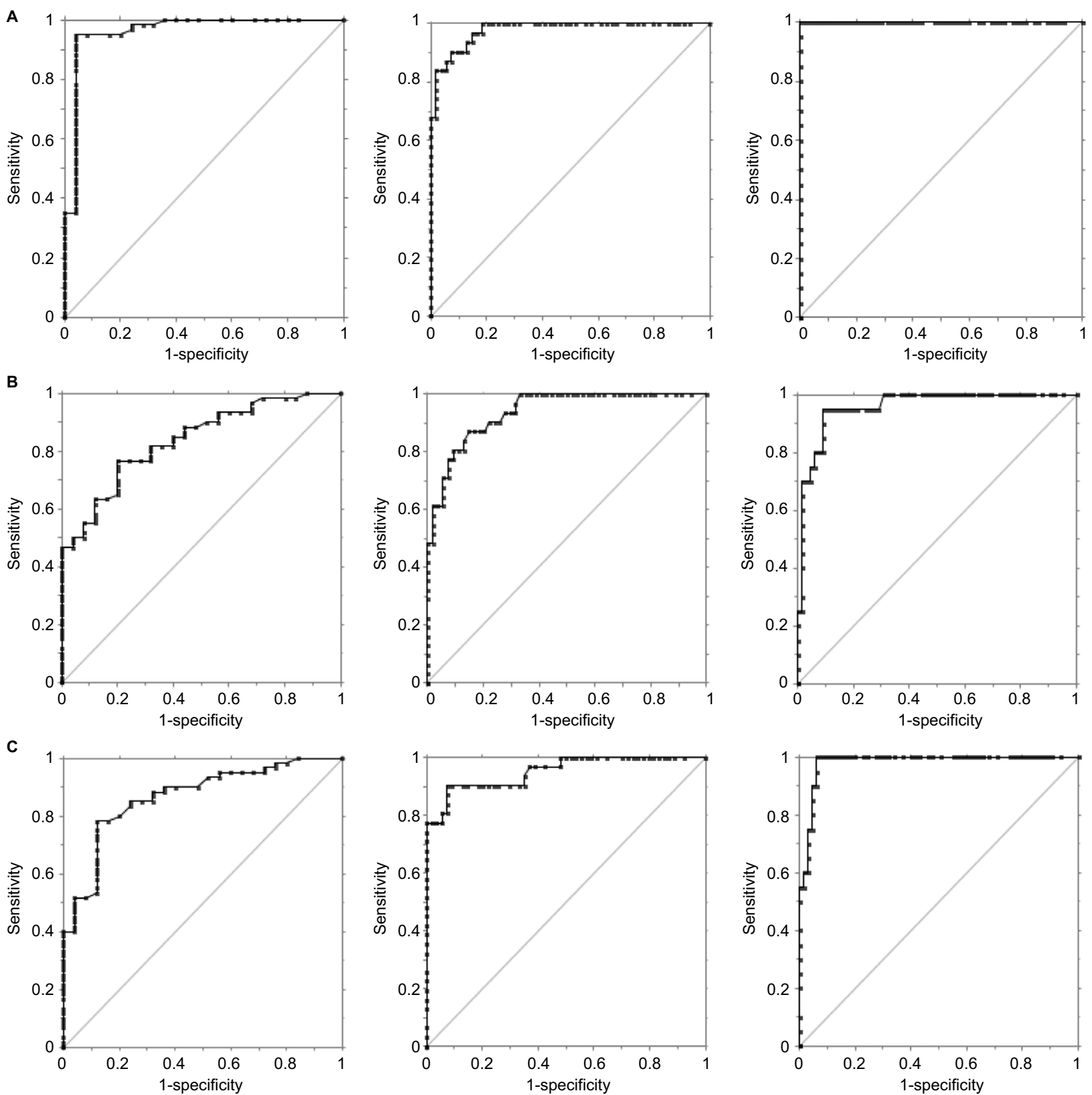

Figure 4 ROC plots of different $\mathrm{AHI}$ cutoffs (5, 15, and 30 columns, respectively).

Notes: (A) The simultaneous (in-laboratory) PSG (reference PSG) and PDX (AUC =0.96, 0.98, I.0, respectively); (B) the in-laboratory PSG and at-home PDX (AUC =0.84, $0.94,0.96$, respectively); and (C) the reference and separate PSGs (AUC $=0.87,0.95,0.98$, respectively).

Abbreviations: ROC, receiver operating characteristic; AUC, area under the ROC curve; PSG, polysomnography; AHI, apnea hypopnea index.

On the other hand, this design limits the study, because no direct event-by-event comparison of the simultaneous PG/ PSG measurements could be accomplished. The simultaneous measurements with different oximetry boards (Alice 5: Masimo, PDX: Nonin) showed slightly divergent results in mean saturation. This may have an influence on hypopnea scoring, according to the desaturation threshold. As expected, because of the different time base (total recording time vs total sleep time), the apnea index in the PDX evaluation was lower, yet the hypopnea index was almost identical, resulting from a slightly higher absolute number of scored hypopneas.
Compared to attended, in-laboratory PSG, there was a very good diagnostic agreement between the PDX and the reference PSG and very few $(<3 \%)$ cases of AHI over- or underestimation. The diagnostic agreement between the PM at home and the in-laboratory attended PSG showed a relevant underestimation in $10.6 \%$ and overestimation in $5.9 \%$ of the cases; this is quite comparable to the degree of under- and overestimation between 2 different PSGs. In accordance with the AASM 2007 recommendation, this study shows that it is reasonable not to exclude the diagnosis of OSA in symptomatic patients with high pretest probability, because 
in $10 \%$ of the cases, a false-negative finding could occur during a home PM assessment.

There were no significant differences in the composite AHI values in any of the conditions. One strength of the study is the randomization of the order of the home and in-laboratory tests. This minimized the impact of night to night variability. ${ }^{23}$ Another strength is the inclusion of simple snorers. Although they were younger, they did not differ in gender, anthropometric measurements, blood pressure, and ESS from those suspected of having OSA. Contrary to some previous studies, the approach of this study avoided the comparison of sleep recordings not performed on the same night, avoiding the bias of night to night variability. There may be a temporal variability in the intensity of sleep disordered breathing when sleep studies are performed on different nights. ${ }^{24,25}$ The scoring criteria used in the study followed AASM clinical guidelines of $2007,{ }^{17}$ which proposed home sleep testing in patients with high pretest probability of OSA, a lack of co-morbidities, and when the testing is managed by a trained sleep specialist. In between, the scoring criteria were revised ${ }^{26}$ and differed in terms of the alternative hypopnea scoring rule with an amplitude criterion of $30 \%$ reduction. The measurements by using the alternative hypopnea rule from the 2007 guidelines were evaluated, and it is believed that the presented results will not deviate substantially when rescored with updated hypopnea recommendations.

A good agreement was shown between the Alice PDX data and PSG data when both AASM 2007 definitions of hypopnea were used.

In 2009, the Center for Medicare and Medicaid Services accepted PM for the diagnosis of sleep apnea. ${ }^{27}$ The presented findings are in accordance to these recommendations, and the results of this study add knowledge to the field and show the validity of a home sleep study with the Alice PDX PM.

\section{Conclusion}

In a population with a high suspicion of OSA, the Alice PDX showed a high level of diagnostic agreement with a simultaneous PSG and performed valid home diagnostic studies for OSA. If manually scored, the portable device can be used by sleep specialists for diagnosing moderate-to-severe obstructive sleep apnea in cases with a high pretest probability for the disease over a wide range of disease severity. The technology can be deployed reliably outside of the sleep laboratory setting. Further studies with this technology in populations with co-morbidities are needed.

\section{Acknowledgments}

The authors would like to thank Jeff Jasko who contributed to the statistical data analysis and Karl-Heinz Rühle for his contribution on the study conception. This work was financially supported and designed by Philips/Respironics.

\section{Disclosure}

The company had no influence on the data acquisition, study conduct, and interpretation of the data. The authors report no conflicts of interest in this work.

\section{References}

1. Patel SR, White DP, Malhotra A, Stanchina ML, Ayas NT. Continuous positive airway pressure therapy for treating sleepiness in a diverse population with obstructive sleep apnea: results of a metaanalysis. Arch Intern Med. 2003;163:565-571.

2. Lacasse Y, Bureau MP, Series F. A new standardised and selfadministered quality of life questionnaire specific to obstructive sleep apnoea. Thorax. 2004;9:494-499.

3. Barb F, Pericas J, Munoz A, Findley L, Antó JM, Agustí AG. Automobile accidents in patients with sleep apnoea syndrome. Am J Respir Crit Care Med. 1998;158:18-22.

4. Marin JM, Agusti A, Villar I, et al. Association between treated and untreatedobstructive sleep apnea and risk of hypertension. JAMA. 2012;307:2169-2176.

5. Gami AS, Pressman G, Caples SM, et al. Association of atrial fibrillation and obstructive sleep apnea. Circulation. 2004;110:364-367.

6. Shahar E, Whitney CW, Redline S, et al. Sleep-disordered breathing and cardiovascular disease: Cross-sectional results of the Sleep Heart Health Study. Am J Respir Crit Care Med. 2001;163:19-25.

7. Arzt M, Young T, Finn L, Skatrud JB, Bradley TD. Association of sleepdisordered breathing and the occurrence of stroke. Am J Respir Crit Care Med. 2005;172:1447-1451.

8. Ancoli-Israel S, DuHamel ER, Stepnowsky C, Engler R, Cohen-Zion M, Marler M. The relationship between congestive heart failure, sleep apnea, and mortality in older men. Chest. 2003;124:1400-1405.

9. Young T, Palta M, Dempsey J, Skatrud J, Weber S, Badr S. The occurrence of sleep-disordered breathing among middle-aged adults. $\mathrm{NEngl}$ J Med. 1993;328:1230-1235.

10. Peppard PE, Young T, Barnet JH, Palta M, Hagen EW, Hla KM. Increased prevalence of sleep-disordered breathing in adults. Am J Epidemiol. 2013;177:1006-1014.

11. Heinzer R, Vat S, Marques-Vidal P, et al. Prevalence of sleep-disordered breathing in the general population: the HypnoLaus study. Lancet Respir Med. 2015;3(4):310-318.

12. Kapur V, Strohl KP, Redline S, Iber C, O'Connor G, Nieto J. Underdiagnosis of sleep apnea syndrome in U.S. communities. Sleep Breath. 2002;6:49-54.

13. Kushida CA, Littner MR, Morgenthaler T, et al. Practice parameters for the indications for polysomnography and related procedures: an update for 2005. Sleep. 2005;28:499-521.

14. Ferber R, Millman R, Coppola M, et al. Portable recording in the assessment of obstructive sleep apnea. Sleep. 1994;17:378-392.

15. Collop NA, Anderson WM, Boehlecke B, et al. Clinical guidelines for the use of unattended portable monitors in the diagnosis of obstructive sleep apnea in adult patients. Portable Monitoring Task Force of the American Academy of Sleep Medicine. J Clin Sleep Med. 2007;3:737-747.

16. Collop NA, Tracy SL, Kapur V, et al. Obstructive Sleep apnea Devices for Out-Of-Center (OOC) testing: technology Evaluation. J Clin Sleep Med. 2011;7:531-548.

17. Iber C, Ancoli-Israel S, Chesson A, Quan SF. The AASM manual for the scoring of sleep and associated events: rules, terminology and technical specifications. Westchester: American Academy of Sleep Medicine; 2007.

18. White DP, Gibb TJ, Wall JM, Westbrook PR. Assessment of accuracy and analysis time of a novel device to monitor sleep and breathing in the home. Sleep. 1995;18:115-126. 
19. Driver H, Pereira E, Bjerring K, et al. Validation of the MediByte ${ }^{\circledR}$ type 3 portable monitor compared with polysomnography for screening of obstructive sleep apnea. Can Respir J. 2011;18:137-143.

20. Sunnergren O, Broström A, Svanborg E. Positional sensitivity as a confounder in diagnosis of severity of obstructive sleep apnea. Sleep Breath. 2013;17:173-179.

21. Kingshott RN, Douglas NJ. The effect of in-laboratory polysomnography on sleep and objective daytime sleepiness. Sleep. 2000;23: 1109-1113.

22. Magalang UJ, Chen NH, Cistulli PA, et al; SAGIC Investigators. Agreement in the scoring of respiratory events and sleep among international sleep centers. Sleep. 2013;36:591-596.

23. Meyer TJ, Eveloff SE, Kline LR, Millman RP. One negative polysomnogram does not exclude sleep apnea. Chest. 1993;103:756-760.
24. Masa JF, Corral J, Pereira R, et al. Effectiveness of home respiratory polygraphy for the diagnosis of sleep apnoea and hypopnoea syndrome. Thorax. 2011;66:567-573.

25. Quintana-Gallego E, Villa-Gil M, Carmona-Bernal C, et al. Home respiratory polygraphy for diagnosis of sleep-disordered breathing in heart failure. Eur Respir J. 2004;24:443-448.

26. Berry RB. Rules for scoring respiratory events in sleep: update of the 2007 AASM Manual for the Scoring of Sleep and Associated Events. Clin Sleep Med. 2012;8(5):597-619.

27. Centers for Medicare and Medicaid Services, www.cms.gov. Decision Memo for Sleep Testing for Obstructive Sleep Apnea (OSA) (CAG-00405N), 2009. Available from: https:/www.cms.gov/medicarecoverage-database/details/nca-decision-memo.aspx?NCAId=227\&ver $=11 \&$ NcaName=Sleep+Testing. Accessed March 3, 2009.

\section{Publish your work in this journal}

Nature and Science of Sleep is an international, peer-reviewed, open access journal covering all aspects of sleep science and sleep medicine, including the neurophysiology and functions of sleep, the genetics of sleep, sleep and society, biological rhythms, dreaming, sleep disorders and therapy, and strategies to optimize healthy sleep. The manuscript
Dovepress

management system is completely online and includes a very quick and fair peer-review system, which is all easy to use. Visit http://www. dovepress.com/testimonials.php to read real quotes from published authors. 